\title{
ESTUDO SOBRE A PERCEPÇÃO DO CLIMA ORGANIZACIONAL DO CENTRO CIRÚRGICO DE UM HOSPITAL ESPECIALIZADO*
}

Wilza Carla Spiri**

SPIRI, W.C. Estudo sobre a percepção do clima organizacional do centro cirúrgico de um hospital especializado.

Rev.latino-am.enfermagem, Ribeirão Preto, v. 6, n. 1, p. 11-14, janeiro 1998.

O presente estudo tem o objetivo de identificar como o grupo de funcionários recém-admitidos no centro cirúrgico de um hospital especializado, percebe o clima organizacional existente, utilizando uma abordagem qualitativa. Como referencial teórico para interpretar o clima organizacional utilizamos os conceitos de CHIAVENATO, que define clima organizacional como meio interno de uma organização e que através de sua experienciação pelos participantes influencia o comportamento dos mesmos, podendo ser favorável, desfavorável e neutro. Os discursos reiteram um clima organizacional favorável, considerando o referencial teórico adotado.

UNITERMOS: clima organizacional, centro cirúrgico

\section{1 - INTRODUÇÃO}

A malformação congênita de lábio e palato, ocorre da quarta à décima semana de gestação, período em que se formam as estruturas labiais e palatinas.

É considerada a terceira malformação congênita mais incidente na população. Existe diferenças da incidência de acordo com o grupo étnico, incidindo mais na raça amarela (um para cada quinhentos nascimentos) e menos na raça negra (um para cada dois mil nascimentos). No Brasil essa incidência é de que a cada seiscentos e cinqüenta nascimentos, um apresente a fissura de lábio e ou palato.

Não existe uma etiologia definida, caracterizando-se como um problema de causa multifatorial, que envolve um fator de hereditariedade associado a causas ambientais, como fatores nutricionais maternos, uso de drogas, radiações e estresse durante a embriogênese.

O Hospital de Pesquisa e Reabilitação de Lesões Lábio-Palatais da Universidade de São Paulo, Campus Bauru, único da América Latina e Centro de Referência do Ministério da Saúde, tem a finalidade precípua de prestar assistência global ao portador de deformidades crânio-faciais, com ênfase nas fissuras lábio-palatais, independentemente de sua condição sócio-econômica, faixa etária, sexo, raça e credo; buscando sua reabilitação na sociedade.
Este processo é lento, envolve fases que consideram o crescimento e desenvolvimento do indivíduo que necessita do acompanhamento de uma equipe interdisciplinar que atua de forma a prestar atendimento abrangendo os aspectos físicos, estéticosfuncionais e psicossociais.

Estima-se hoje em duzentos e oitenta mil os portadores de lesões lábio-palatais no país, sendo que em tratamento, nesse serviço, estão registrados cerca de vinte e seis mil, resultando na existência de uma demanda reprimida considerável.

Por esses motivos, fizeram-se necessárias ampliações e mudanças no atendimento para diminuir a demanda reprimida. Portanto, para concretizar o aumento de atendimento proposto, a partir da ampliação física e tecnológica, a instituição investiu em recursos humanos, nas diversas áreas, abrindo processo seletivo.

$\mathrm{Na}$ enfermagem foram selecionadas três enfermeiras e dezoito auxiliares de enfermagem. Destas, foram destinadas 10 auxiliares de enfermagem para $o$ Centro Cirúrgico, para que a demanda cirúrgica fosse aumentada.

Visualizando o Centro Cirúrgico como sistema sócio-técnico-estruturado aberto, que recebe o ser humano que necessita da intervenção cirúrgica e visa devolvê-lo à sociedade com capacidade para viver de forma plena $\mathrm{e}$ sem ter sido colocado em situações de risco (JOUCLAS, $1987)^{3}$, preocupa-nos a capacitação dos recursos humanos

\footnotetext{
* Trabalho apresentado na sessão de Temas Livres do 5 SIBRACEn

** Enfermeira responsável pelo Centro Cirúrgico do HPRLLP-USP - Bauru. Mestranda do programa de Pós-Graduação EE-USP - Área de concentração: Administração dos Serviços de Enfermagem
} 
necessários para esse trabalho, não apenas do ponto de vista técnico, mas no sentido mais amplo de participação.

Segundo CHIAVENATO $(1994)^{2}$, participação é um processo que exige o envolvimento mental e emocional das pessoas para o alcance dos objetivos propostos.

Portanto, ao recebermos os auxiliares de enfermagem (em número de dez) destinados a essa unidade, realizamos treinamento geral e específico na unidade e esclarecemos o grupo já atuante, quanto ao recebimento dos novos funcionários.

Este programa constou de aulas teóricas com noções de aspectos biológicos (embriologia, etiologia, incidência e classificação das fissuras), psicossociais, filosofia da Instituição e do Serviço de Enfermagem, com ênfase no trabalho em equipe e Sistematização da Assistência de Enfermagem Perioperatória (SAEP).

Paralelamente a isso, efetuamos uma reunião com a equipe atuante esclarecendo quanto ao recebimento dos novos funcionários para a possibilidade do aumento da demanda de pacientes e no que isto significaria para a Instituição e a contribuição ao processo de reabilitação do portador de deformidades cranio-faciais a nível nacional.

Considerando que o Centro Cirúrgico, faz parte da organização e esta possui uma cultura, que segundo BERNARDES (1984)" "indica o complexo de comportamento, das crenças, dos valores espirituais e materiais partilhados pelos membros de uma sociedade". Esta cultura possui subculturas que são ramificações e que refletem o modo de pensar e agir dos membros desta, influenciando o comportamento dos indivíduos.

Considerando também que as subculturas ou culturas organizacionais, possuem um clima, e que segundo CHIAVENATO $(1994)^{2}$ clima "é o meio interno da organização, a atmosfera psicológica e característica que existe em cada organização", constituindo de um ambiente humano, não podendo ser tocado ou visualizado, mas percebido, podendo ser favorável quando proporciona satisfação das necessidades pessoais dos participantes produzindo elevação do moral interno, desfavorável quando proporciona frustração das necessidades pessoais contribuindo para a baixa do moral interno e neutro quando este clima é indiferente aos participantes, levando-os a não se importarem com o que aconteça na organização. Isto influência a motivação, o desempenho humano e a satisfação no trabalho.

Existe ainda um peso do informal que TRAGTEMBERG (1989) ${ }^{4}$ declara como sendo de grande valor nas organizações porque pode ser oposto ao formal e permeia todo o processo de comunicação e ajustamento do indivíduo na organização. Pretendemos, a partir da realidade já explicitada, realizarmos um estudo que tem por objetivo:
- Identificar como o grupo de funcionários recémadmitidos no Centro Cirúrgico, percebe o clima organizacional existente.

\section{2 - METODOLOGIA}

Para atingirmos nosso objetivo utilizaremos uma metodologia qualitativa, como estratégia de análise de uma situação real, para extrairmos da experiência desse grupo de auxiliares de enfermagem, a percepção do clima organizacional existente.

\section{1 - Proposta do estudo}

Neste estudo, tentaremos atingir nosso objetivo adotando como técnica para captação da realidade, entrevistas com o grupo de auxiliares de enfermagem recém-admitidos no centro cirúrgico do Hospital de Pesquisa e Reabilitação de Lesões Lábio-Palatais, da Universidade de São Paulo.

Assim, as entrevistas foram realizadas com sete auxiliares de enfermagem que concordaram em participar do estudo, após explicarmos o objetivo, a dinâmica da entrevista e a garantia do anonimato. Solicitamos autorização para gravarmos as entrevistas, esclarecendo que este procedimento facilitaria a realização do estudo.

Efetuamos as entrevistas no local de trabalho do funcionário (Centro Cirúrgico) em um sábado, pois neste dia não são programados procedimentos eletivos. Procuramos tornar o ambiente o mais confortável possível e de maneira informal tentamos não impor barreiras a comunicação com o entrevistado. As entrevistas foram realizadas uma única vez com cada sujeito do estudo.

Utilizamos 4 questões norteadoras para resgatarmos a percepção que esses funcionários possuem sobre o clima organizacional:

- Como você sente o seu ambiente de trabalho?

- Como você percebe os colegas admitidos juntamente com você no trabalho?

- Como você percebe os colegas que já atuavam na instituição antes de você?

- Como você se percebe nesse ambiente de trabalho?

Para assegurarmos o anonimato dos depoimentos, denominamos de AE1, AE2, AE3, AE4,AE5, AE6 e AE7 os sujeitos dos diferentes discursos.

\section{3 - INTERPRETAÇÃO}

Nesse momento, procuramos interpretar, a partir de nosso vivencial, o fenômeno doado da percepção das auxiliares de enfermagem entrevistadas, resgatando dos 
discursos as falas significativas em relação ao clima organizacional existente no Centro Cirúrgico do Hospital de Pesquisa e Reabilitação de Lesões Lábio-Palatais.

Para interpretarmos os discursos colhidos através das entrevistas e posterior transcrição das mesmas, lemos por diversas vezes cada um deles e tentamos resgatar, desses discursos, as falas significativas que emergiram com o tema.

Dessa forma, as falas dos auxiliares de enfermagem foram reduzidas em unidades de significados e categorizadas em quatro temas: RELACIONAMENTO INTERPESSOAL, CONDIÇÕES DE TRABALHO, RECURSO MATERIAL E PERTENCER AO GRUPO.

Portanto, a partir do referencial teórico, interpretaremos o fenômeno da percepção do clima no Centro Cirúrgico pelos auxiliares anteriormente descritos.

\section{OS TEMAS}

Assim, o tema RELACIONAMENTO INTERPESSOAL revela a percepção de um clima favorável no sentido em que compreende: aceitação, receptividade e comprometimento, tanto entre o próprio grupo recém-admitido, como entre o grupo recém admitido e o grupo já atuante. As falas explicitam isto:

"As pessoas nos tratam bem, procuram crescer e desempenhar um bom trabalho",... o grupo antigo é bastante experiente e com boa vontade para ajudar". (AE1)

"O grupo se entrosa bem, ajudando uns aos outros, o pessoal é muito bom"; ... "existe colaboração de todas"; ... "o grupo antigo explica tudo para gente, nos ajudam bastante”. (AE3)

"O pessoal dá uma boa assistência e estão sempre nos orientando",... "pessoal antigo tem preocupação conosco e sentem-se mais responsáveis pelo serviço tendo que ter mais atenção agora do que antes". (AE5)

"O pessoal é interessado em trabalhar e aprender",;.. "considero um grupo bom ";... "o pessoal antigo ensina e ajuda". (AE6)

Ainda de acordo com CHIAVENATO $(1994)^{2}$ o clima depende, dentre outros aspectos, da escolha da equipe, do preparo e treinamento da equipe e de participação pessoal. Isto nos leva a crer, que o trabalho prévio de treinamento do grupo recém-admitido foi de fundamental importância para que pudessem se conhecer, obter noções da estrutura organizacional e da ênfase dada ao trabalho em equipe, para a reabilitação do portador de fissura lábio-palatal. Acreditamos também que os esclarecimentos prestados aos funcionários já atuantes na unidade, a respeito da necessidade do aumento da demanda cirúrgica, juntamente com a necessidade de ampliarmos o quadro de pessoal solicitando a colaboração de todos neste processo, foram decisivos para que o relacionamento interpessoal fosse favorável, conforme revelam os discursos acima.

Outro tema resgatado nos depoimentos foi: CONDIÇÕES DE TRABALHO, que a partir das falas, revela serem exercidas dentro de um ambiente favorável, no sentido em que traduz: calor humano, satisfação e comprometimento. Assim temos:

"O ambiente é tranqüilo",... "é bom, sadio",... "possibilita o crescimento",... "possui normas". (AE1)

"É um ambiente gostoso, diferente $e$ tranqüilo";... "é gratificante trabalhar aqui". (AE2)

Conforme as falas, podemos apreender que este tema resgatado (CONDIÇÕES DE TRABALHO) revelou que são proporcionadas condições de trabalho, como possibilidade de crescimento e segurança, caracterizado como clima positivo, pois o clima depende também da estrutura interna do serviço e das oportunidades dadas aos integrantes nesta estrutura (CHIAVENATO, 1994) ${ }^{2}$ o que durante o treinamento foi clarificado ao grupo recém-admitido e percebido pelo mesmo no decorrer do trabalho .

Outro tema que emergiu, diz respeito a RECURSOS MATERIAIS. Embora durante a entrevista não abordássemos esta questão, algumas auxiliares de enfermagem levantaram este tema, pois segundo suas percepções o recurso material em quantidade suficiente é fator de clima favorável, gerando satisfação no trabalho e possibilitando um desempenho de boa qualidade. As falas a seguir explicitam isto:

"A gente tem tudo o que precisa para o trabalho". (AE2)

"Aqui temos tudo, pois é um hospital de primeiro mundo". (AE5)

É importante considerar que estas falas são das auxiliares de enfermagem que já vivenciaram realidades onde a carência de recurso material era fator importante no desempenho do trabalho.

Resgatamos também, a partir das falas das auxiliares de enfermagem, o quarto tema: PERTENCER AO GRUPO. Esse tema refere-se à percepção dos profissionais de sentirem-se incluídas na estrutura organizacional. De acordo com o referencial teórico adotado, apreende-se que há um clima favorável, emergindo as percepções de: aceitação, satisfação e comprometimento em relação às colegas e ao trabalho desenvolvido. Assim temos:

..." me sinto realizada porque batalhei muito para isso",... "aqui tudo é organizado estruturado". (AE3)

..." "me sinto bem aqui",... "é um trabalho muito importante para o paciente",... "estou fazendo aquilo que gosto". (AE7) 
A auxiliar de enfermagem AE5, explicita uma preocupação em relação à sua aceitação pelo grupo pois revela que:

..."tinha uma preocupação em saber com quem tirar minhas dúvidas, pois tinha medo que isto virasse gozação". (AE5)

Pertencer ao grupo, também é uma necessidade básica do ser humano, sem a qual não se sente seguro para realizar suas atividades. Compreendemos, a partir deste tema, a premência das auxiliares em sentirem-se aceitas, incluídas, como parte da equipe, despojando-se às vezes de suas características pessoais para "revestiremse" da característica do grupo, o que mais rapidamente as tornaria integradas a equipe de trabalho, dentro deste ambiente específico.

\section{CONSIDERAÇÕES FINAIS}

Nossa inquietação foi identificar, como o grupo de funcionários recém-admitidos no centro cirúrgico do HPRLLP, percebe o clima organizacional existente. Considerando a análise qualitativa, buscamos o fenômeno a partir dos sujeitos (auxiliares de enfermagem) que vivenciam a situação de serem recém-admitidos.

Os discursos revelaram um clima organizacional favorável, desvelado pelos temas: relacionamento interpessoal, condições de trabalho, recursos materiais e pertencer ao grupo.

Consideramos porém, importante salientar que nossa participação, enquanto responsável pela equipe de enfermagem, concomitantemente ao papel de pesquisadora, pode ter sido fator interveniente para as auxiliares de enfermagem explicitarem, com clareza, as dificuldades e problemas por elas vivenciados.

Acreditamos também, que o pouco tempo de convívio deste grupo recém-admitido com o grupo já atuante, ainda não possibilitou um conhecimento das pessoas, fazendo com que a análise tenha sido superficial.

No entanto nossa percepção, enquanto responsável pela unidade de centro cirúrgico, para com este grupo de auxiliares de enfermagem recém-admitido, é de que é um grupo que busca adaptar-se e relacionar-se de maneira satisfatória. Com o desvelamento do fenômeno, novos horizontes e novas inquietações emergem, para conhecermos o quanto isto reflete na cultura da organização.

\section{STUDY ON THE PERCEPTION OF THE ORGANIZATION CLIMATE OF THE SURGICAL CENTER IN A SPECIALIZED HOSPITAL}

The aim of this study is to identify how a new team of the surgical center staff in a specialized hospital perceive the organization climate. A qualitative approach was utilized. As a theoretical reference to measure the organization climate, we have used CHIAVENATO, that defines organization climate as the interior of an organization that influences its members' behavior. The organization climate could be favourable, unfavourable or neutral. The speechs showed a favourable organization climate considering the adopted methodology.

KEY WORDS: organization climate, surgical center

\section{ESTUDIO SOBRE LA PERCEPCIÓN DEL CLIMA ORGANIZACIONAL DEL CENTRO QUIRÚRGICO DE UN HOSPITAL ESPECIALIZADO}

El presente estudio tiene el objetivo de identificar cómo el grupo de funcionarios recién admitidos en el centro quirúrgico denota el clima organizacional existente, utilizando un abordaje cualitative. Como referencial teórico para interpretar el clima organizacional utilizamos los conceptos de CHIAVENATO, que define clima organizacional como el medio interno de una organización y que a través de su experiencia los participantes influéncian el comportamiento de los mismos, pudiendo ser favorable, desfavorable y neutro. Los discursos revelaron un clima organizacional favorable, considerándo el referencial teórico adoptado.

TÉRMINOS CLAVES: clima organizacional, centro quirúrgico

\section{REFERÊNCIAS BIBLIOGRAFICAS}

01. BERNARDES, C. Sociologia aplicada à administração. São Paulo: Atlas, 1984.

02. CHIAVENATO, I. Gerenciando pessoas: o passo decisivo para a administração participante. 2. ed. São Paulo: Makron Books, 1994.
03. JOUCLAS, V.M.G. Análise da função do circulante de sala de operações de acordo com a metodologia sistêmica de organização de recursos humanos. São Paulo, 1987.214p. Tese (Doutorado) - Escola de Enfermagem, Universidade de São Paulo.

04. TRAGTEMBERG, M. Administração, poder e ideologia. São Paulo: Cortez, 1989. 